\title{
LOW-COST 4D BIM MODELLING A COMPARISON BETWEEN FREECAD AND COMMERCIAL SOFTWARE
}

\author{
D. Di Donato ${ }^{1 *}$, M. Abita ${ }^{1}$ \\ ${ }^{1}$ DICEAA, Department of Civil, Construction-Architectural and Environmental Engineering \\ University of L'Aquila, 67100 L'Aquila, Italy - (danilo.didonato, matteo.abita)@univaq.it
}

\section{Commission II}

KEY WORDS: 4D BIM Modelling, FOSS, Freecad, ProjectLibre, Steel Structures

\begin{abstract}
:
The paper aims to investigate the potential inherent in a FOSS (Free and Open Source Software) approach for the 4D BIM modelling using Freecad. In order to reach this goal it shows a comparison of Freecad features with those of commercial software, considering the evaluation of the effective application of this Open Source software in the professional environment, and highlighting the progress in the FOSS BIM area, that still represents an unexplored study field if compared to the vast publications related to BIM modelling that occurred in the last two decades. To this end, the study has been carried out on a singular case study, a steel canopy which has been designed for the urban renewal of a public space in Teramo. Despite its size, the canopy required the definition of complex details. Its structural system has addressed the study to compare Freecad with some software dedicated to steel structures or particularly suitable for the modelling of this specific structural typology: Tekla Structures and Sketchup. Starting from a concise historical reconstruction of the FOSS spread, the paper introduces a brief overview of the potential of Freecad in terms of BIM modelling - also proposing an operational modality to facilitate the drawing of BIM elements within the software - and finally reaching to the examination of three simulations which has been carried. This comparison can be useful to establish the current state of development of Freecad in the field of 4D BIM.
\end{abstract}

\section{OPEN SOURCE AND DIGITAL REVOLUTION}

The paradox of Robinson Crusoe, which Karl Popper adopted in "The open society and its enemies" to describe the necessarily public character of science (Popper, 1974), has been used by Alessandro Frigeri and Gisella Speranza to establish a comparison between the control of theory at the basis of the scientific method, grounded on the reproducibility of experiments, and the IT procedures that govern the creation of Open Source software (Frigeri \& Speranza, 2011).

For the commercial software the source code is not released, therefore the users (end-users) are restricted to the condition of simple consumers and they must rely on the correctness of its operational sequence and the results that it proposes, being unable both to govern or to control it. They are subjugated by a technology, scarcely knowable and verifiable, in possession of few depositories, perched in the isolation of an imaginary turris eburnea that associate them not only to the Robinson of Karl Popper, but also to the enigmatic figure of Jorge of Burgos, the jealous guardian of knowledge enclosed in the labyrinth- library of "The name of the rose" (Eco, 1980).

The alternative paradigm of the free software, that has born on the push of the hacker movement, has opposed to the restrictions imposed by the monopoly of the big IT companies (Levy, 1984, Himanen, 2001, Wayner 2000, Raymond et al. 2003, Graham 2004, Di Bona \& Ockman 2008). Its most wellknown results are the free/libre text editor Gnu Emacs and the Operating System (OS) Gnu / Linux (Stallmann 2018a, b, Kelty 2008). In particular, this OS, originated by the union of the GNU operating system and the Linux kernel, represents one of the several links that the free software movement has established with the following Open Source movement (Markoff 2005, Open Source Initiative 2018). Despite the countless frictions and controversies, fostered over the years by the charismatic figures that liven up the two parts, in particular Richard R. Stallman and Eric S. Raymond (Stallman et al. 2002, Raymond 1998), it is sometimes difficult to identify a clear dividing line between them.

In any case, Open Source owes a great tribute to the free software movement for the introduction of the "copyleft" - also created by Stallman and the Free Software Foundation founded by him - an innovative way of distributing software and documents, in order to "copy the program, modify the program, and distribute modified versions - but not permission to add restrictions of their own" (Stallmann 2018c, Free Software Foundation 2018). The copyleft finds its substantial and legal translation in the GNU General Public License or GPL, the license that will become the foundation for the others that will be used over the years for the release of Open Source software and documents (Stallman et al. 2002).

Another fundamental step is the innovation introduced by Linus Torvalds for the "subversive" project of the Linux kernel, released under the GPL license; the Swedish IT technician has invented a development methodology that has been certainly original and which hasn't been organized on a rigid hierarchical control of software packages, but on a horizontal sharing, extended to a very large community, involved in the realization of substantial parts of the software. Raymond has recognized the experimental value of the Torvalds method, and he has enhanced its original character and pervasive effectiveness,

\footnotetext{
* Corresponding author
} 
resorting to the contrast between established and traditional practices of software development, the commercial ones in particular, similar to the construction of large cathedrals, and the innovative method of Torvalds, where the control of chaos and the widespread participation of developers have seemed to recall the image of a bazaar (Raymond 1999).

The "Unintended Consequences" produced by the introduction of the GNU GPL and the work methodology proposed by Linus Torvalds have represented for Manuel Delanda an "institutional environment" for a new economic system based on the production and exchange of Open Source software (DeLanda 2001), in order to constitute the foundation of its definitive affirmation.

Another aspect that has favoured the success of the free software and the Open Source movements is the sudden spread of the Internet and the WEB, "a completely new world" (Floridi 1995), "a Pygmalion" which is able to establish and to organize new virtual communities that can participate and collaborate in the realization of ambitious shared projects. Therefore the Internet platform has represented the intangible support for the constitution of the institutional environment which has been based on a deep and radical "Digital Revolution", in the Information and Communication Technology (ICT) sector.

\section{THE BIM IN FREECAD}

The development model proposed by Torvalds was the driving force for the definitive affirmation of the Open Source world; without a doubt the bazaar prototype has been strictly related to a significant character of the movement, its capillary and pervasive nature, leading to its many branching that have interested and still affect the different areas of computer programming.

However, within an incredibly rich, manifold and stratified scenario, a field of research almost unexplored and unrelated to experiences of Open Source software remains the Building Information Modelling (BIM). In fact its development is due, in an exclusive form, to big companies of the computer technology. Some software such as B-Processor ("B-processor" n.d.) - a program realised by the Aarus School in collaboration with the Alexandra institute, still in the pre-alpha version but no longer developed since 2015 - or xBIM Toolkit ("xBIM Toolkit," n.d.) - firstly developed in 2007 by prof. Steve Lockley with the subsequent support of Northumbria University in 2009 - have proposed useful tools for the implementation of BIM projects. Another significant initiative is linked to IfcOpenShell, "a free Open Source IFC geometry engine based on OpenCascade Technology". The IfcOpenShell libraries and the OpenCascade Technology represent nowadays an indispensable aid to numerous computer graphics software, both commercial and Open Source ("IfcOpenShell," n.d.; "OPEN CASCADE," n.d.). Among them Freecad has emerged in recent years as one of the few valid free alternatives to proprietary BIM software. This program dated back to January 2001 and its first developer was Jürgen Riegel, preparing at that time to work on an Open Source GOM (Graphical Object Modeler) able to implement Qt multi-platform libraries (Dalheimer, 2002), the Python programming language (Horstmann, 2013) and Open CasCADE. Open CasCADE - a 3D CAD / CAM software development platform (Computer-Aided Design and ComputerAided Manufacturing) and CAE (Computer-Aided Engineering) with an integrated CAD-Kernel - was in origin a commercial software but its proprietary company, the Matra Division, decided to abandon its development plan releasing the code as Open Source. For the software architecture of Freecad Riegel was inspired by Catia V5 by Dassault, well known in the architectural field because Frank Gehry studio used it to manage some of its complex projects ("Gehry, Dassault and IBM Too Day," n.d.). Its inventor thus announced the launch of Freecad on the OpenCascade Forum: "It features some key concepts like Macro Recording, Workbenches, ability to run as a server and as a dynamically loadable applications' extension, and it is designed to be platform independent" ("History - FreeCAD Documentation," n.d.). Werner Mayer, a Riegel's colleague, joined his friend in the Freecad development right away. In 2005 Imetric "donated most of its Mesh Module to FreeCAD and the Open Source community, and since then they used FreeCAD as basis for their sensor system software". Also in 2005 the developers decided to abandon part of the OpenCascade framework, preserving only its kernel and replacing the rest with its own implementation. In 2008 the Belgian architect Yorick van Havre joined the team. He started work on the Draft Module, which allowed the drawing of $2 d$ geometries; he also worked on expanding the FreeCAD documentation. In the last decade contributions to the development have become more and more numerous and fields of interest of the software have extended to new branches, confirming the multidisciplinary character of Freecad since first release versions. This aspect has produced a really complex software architecture which is organized in workbenches corresponding to different work environments of the program. In the last few years this generalist feature of the software also involved the development of a special workbench, specifically dedicated to BIM and edited by van Havre himself ("BIM Workbench - FreeCAD Documentation," n.d.). The BIM workbench was firstly conceived as a simple implementation of the Arch workbench but later separated. The development of this BIM module is following typical dynamics of the Open Source environment: it is based on the principle of sharing libraries that have been developed in other areas, such as the IfcOpenShell; it is grounded on the active collaboration of developers and users' community who test the versions of the specific workbench - monthly or bimonthly released - and guide the development program through a constant verification of the software and a fertile exchange of ideas on possible improvements and implementations, which are promptly proposed on the pages of the Freecad user forum specifically dedicated to the Bim workbench. The current released version of Freecad is the 0.18 ; compared to previous versions, the last has numerous updates including the Qt 5.6.2 and Python 3.6.6 libraries. The implementation of these libraries offers new opportunities for the software development although it has also revealed some problems, for example the incorrect functioning of some macro and complementary workbenches which have been proposed by developers' community. These critical aspects are probably due to the closeness with the release of the last Freecad version; as a consequence some complementary addons have not been adapted to new libraries yet but this gap is presumable/desirable that it can be shortly filled.

The state of art concerning studies focusing on Freecad BIM features is limited and often related to themes not strictly linked to the 4D BIM Modelling (Falck et al., 2012, Logothetis et al., 2017a, Logothetis et al., 2017b, Logothetis et al., 2018).

\section{THE 4D BIM MODELLING}

Time planning is strictly necessary for the successful outcome of an architectural work. The control of building phases, the management of companies and workers sequence, represent fundamental details for a prior organisation, even though time is often an unpredictable parameter for the building field due to the delicate combination of location, resources and people 
involved in the construction process (Srdić and Šelih, 2015). The term 4D means the addition of time specification to a 3D model widening the interactive environment with another extra dimension $(\mathrm{x}, \mathrm{y}, \mathrm{z}, \mathrm{t})$, an experimentation that was firstly tried with CAD facilities. The tool CIFE 4D-CAD, developed at Stanford University in the 1990s (McKinney et al., 1996), was one of the first attempt to link CAD elements to time schedules and CPM (Critical Path Method) diagrams, but apart the advantages, many deficiencies were gradually highlighted in the 4D-CAD applications. Tools like 4D SpaceGen, 4D-GCPSU (Graphical Construction Planning and Site Utilization), 4DMCPRU (Management for Construction Planning and Resource Utilization), all developed in the early 2000s, permitted to analyse space-time clashes and to develop WBS (Work Breakdown Structure) paths oriented to a better resource allocation and site construction management, but the lack of automation in the modelling phase, the impossibility of a collaborative use, the inability of showing provisional requirements and non-physical constraints of a building, made particularly complicated the broad diffusion and usage of these tools (Webb and Haupt, 2005).

Most of these issues have been solved with the arrival of BIM platforms and the diffusion of their more advantageous utilities. The most important features that developed the 4D usage are: information and changeable parameters included in BIM elements that are often automatically inserted avoiding the manual addition necessary in a CAD environment; BIM workflow foresees the direct generation of a $3 \mathrm{D}$ model without respecting $\mathrm{CAD}$ layers hierarchy and saving work time; the possibility to introduce variations and additional information that instantly correct the model in a parametric way; the potential for more specific professionals to work on the same model in a collaborative and simultaneous interaction (Nehad et al., 2017). Therefore BIM environment finally allows the automatic generation of a 4D model that could be continuously modified and improved, but it also includes many other utilities developed by the research in the last ten years. 4D BIM modelling permits time planning visualisation not only through traditional diagrams used by technicians like Gantt charts and PERT (Program Evaluation and Review Technique) layouts, but also through dynamic animations that show construction sequences that could be enjoyed with the tools of the virtual reality in a walk-through experience (Sampaio, 2017). The 4D BIM model is able to be controlled by all the participants to the construction, evaluating time monitoring from the different points of view of technicians developing a decision-making process both for as-planned and as-built evaluations. Indeed one of the most powerful benefits of 4D BIM modelling consists of analysing construction phases in order to check interferences with a virtual simulation of the building site, improving movements of machinery and people, storage and handling of resources, always verifying the respect of safety standards and environmental sustainability (Jupp, 2017).

An important issue that affects the successful outcome of a 4D simulation is represented also by the level of information and details equipped in the modelling phase. It is to be expected that a high level of LOD, about LOD 400, is recommended in order to better organise all the aspects of construction phases, but some authors affirm that it is sometimes necessary to shift between different levels of LOD according to the purposes of 4D BIM simulations, considering "Multi-LOD" evaluations (Guévremont and Hammad, 2018). For instance major stages of construction, especially when a great scale settlement is analysed, do not need a high state of LOD, whereas focus on single and integrated construction phases, particularly affecting building parts or components, require detailed information.
Furthermore during the construction process some features could be changed in the model, as well as some details couldn't be totally predictable due to building site constraints. Therefore it is possible to consider "graphical" and "temporal" LODs during the as-planned and as-built phases, that could be variously changed in the 4D simulation (Boton et al., 2015).

The trend of recent years by major software house is to include 4D BIM utilities in a stand-alone platform, but the construction of a 4D model and the extrapolation of operational data could be also reached with specific plug-in additions. Indeed it is possible to classify three categories of 4D applications: independent stand-alone software like Autodesk Navisworks or Trimble Tekla Structures in which 4D utilities are already integrated; freeware softwares like SketchUp with some 4D functions integrated and others implemented by additional plugins; open-source software like FreeCad, for which 4D utilities must be added with specific applications.

In order to compare these different operational addresses, the contribution aims to evaluate the achievement of a 4D BIM analyse using different digital platforms for the project of a specific case-study.

\section{THE CASE STUDY}

The proposed example is the BIM modelling of a steel canopy designed for the improvement of Corso San Giorgio in Teramo, the main street of a town in the centre of Italy (Fig. 1). This project, designed by architects Giustino Vallese and Dario Magnacca and completed in May 2018, was originally developed by one of the authors of the paper with the use of Sketchup software, in order to verify all the connection systems of steel members and the integration between the structure and technological solutions of envelope. The canopy does not have a considerable extension, because it develops only 180 square meters but it has an irregular shape, with an arrangement of the columns that seems to be apparently chaotic and a plan of the roof that balances between an orthogonal geometry on 3 sides and connections with circular arches at the end of the perimeter, also pierced by a large circular hole to let the light in (Fig. 2). The designers desire to keep the sheltered structure profile as thin as possible led to coherent design choices, such as the edge tapering obtained through the insertion of cantilevered beams and the withdrawal of external columns, as well as technological solutions for the roof slab useful for the containment of the whole structural weight. The need to reduce the construction time and to guarantee the economic sustainability of the work forced the use of dry assembly systems and bolted connections, limiting welding operations to the only phases operated in the fabrication shop prior to the hot

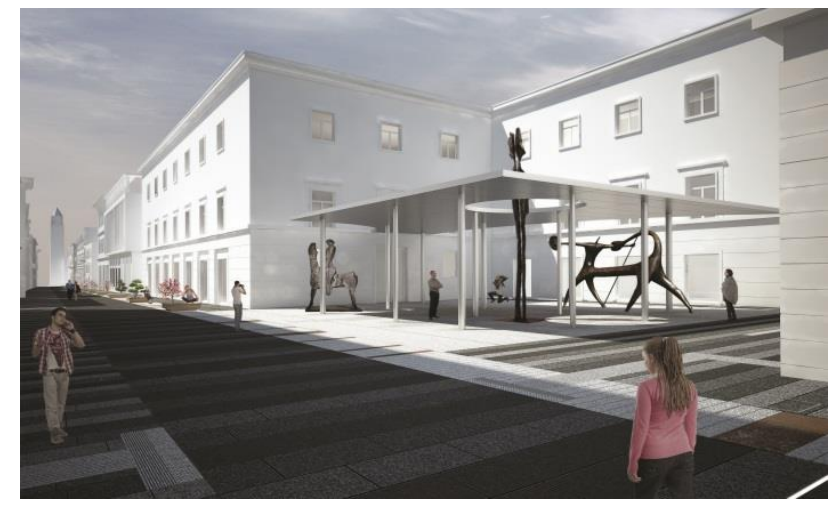

Figure 1. Rendering view of the steel canopy in Teramo (Courtesy of Giustino Vallese and Dario Magnacca) 


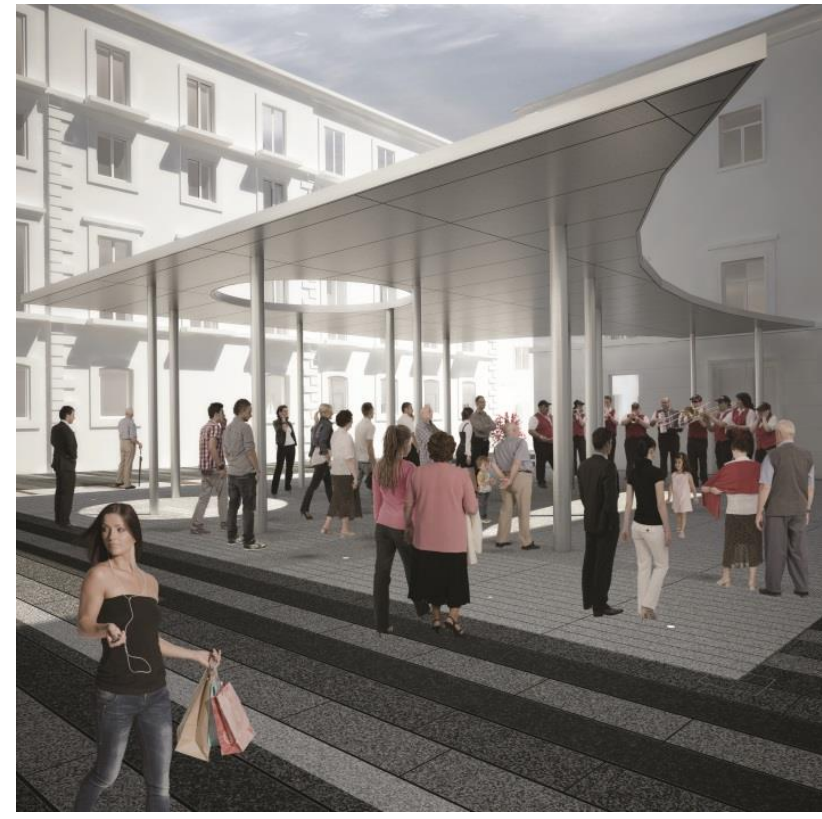

Figure 2. A rendering view of a curved side and the big circular hole inside the steel canopy (Courtesy of Giustino Vallese and Dario Magnacca)

dip galvanization process of steel profiles. The irregular arrangement of the tubular columns, shaped with three circular sections, was also imposed by the discovery in the area of the relics of a previous building demolished at the beginning of the twentieth century, which the municipal authority wanted to preserve. This point also led to the choice of the foundation system, composed by plinths connected by beams, inserted where the archaeological remains did not insist. The metal structure of the roof was organized with the hierarchical arrangement of the main beams, following the rearward perimeter, and a more regular mesh of secondary beams, both stiffened by a system of slender diagonal braces made of $\mathrm{L}$ shaped or U-shaped sections. The perimeter curved profiles had been firstly thought as calendered beams but later, they were replaced by welded pieces of straight profiles aligned to the spring line of the arches, in order to support their curvature. The connection between the circular columns and the main I-beams was solved through the design of a special capital, obtained by the insertion on the head of the columns of I-shaped pieces with large sections, vertically oriented and connected to the ends by octagonal plates. The irregular and complex geometry of the roof required extreme accuracy in the design ofhe numerous connection plates between the diagonal braces and the main and secondary beams.

The containment of the structural weights was achieved through the construction of a wooden floor, that consists of wooden joists, connected to the underlying steel beams through special aluminium plates, and nailed OSB panels. The waterproofing closure of the roof was made of aluminium sheets, connected together by a mechanical interlocking system that avoided drilling operations externally exposed to the weather.

The intrados and the perimeter of the canopy, as well as the tapered parts of the roof, were covered with mirror-finished stainless steel sheets, joined to the steel structure through a special mounting profiles.

The decision to test the potential of Freecad in the 4D BIM field on this specific project was suggested by the complexity of the work which, despite its small size, constitutes a meaningful example to check its flexibility in modeling, the arrangement of irregular geometries and the management of a large number of components. On the other hand, the participation in the design phases of the work was a fundamental prerequisite to be able to deeply consider all the problems related to the construction and to evaluate the validity of the software for the problem solving.

\subsection{The 4D BIM simulation in Freecad}

Before proceeding with the 4D simulation in Freecad, it was necessary to build the model. The ordinary modules for the BIM platform are the Arch and BIM workbenches, both equal, even if the second is implemented with specific commands for the management of the BIM. The modelling process in these two modules requires the design of each individual beam but, in the proposed study case, this mode would have taken a long time, because of the high number of members and the irregular geometry of the structural system that would not allow to proceed to an extensive copying and cloning operations. To overcome this problem, the modelling process resorted to an alternative modality through the use of a complementary addon, Dodo, dedicated to the modelling of steel pipes and profiles. Dodo, like its predecessor Flamingo, allows to assign certain

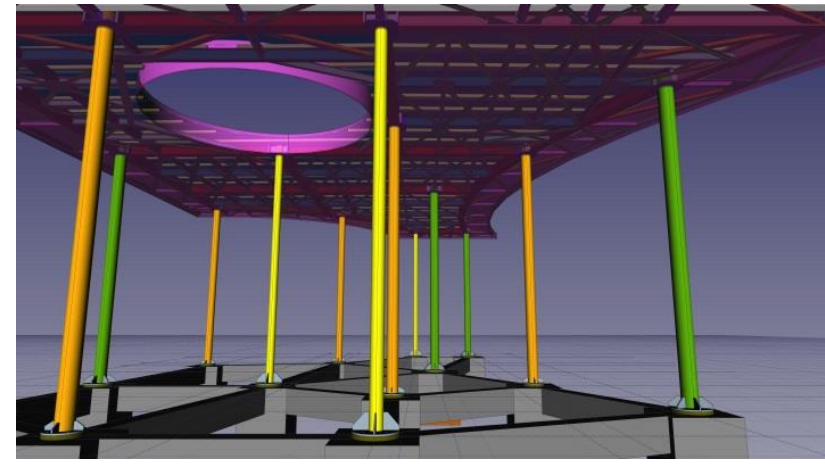

Figure 3. The Freecad BIM Model, a bottom view

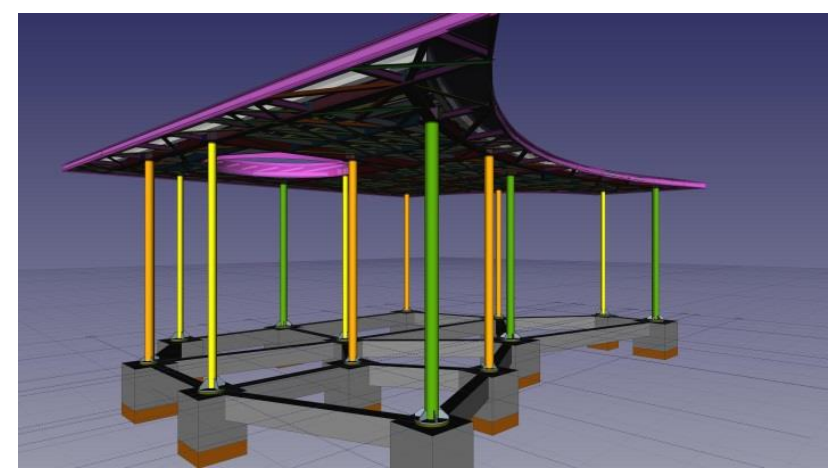

Figure 4. The Freecad BIM Model, a perspective view

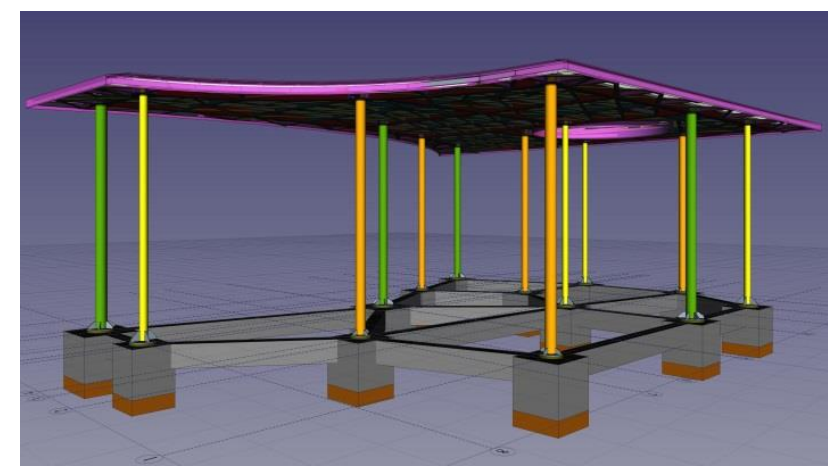

Figure 5. The Freecad BIM Model, a view of a curved side 


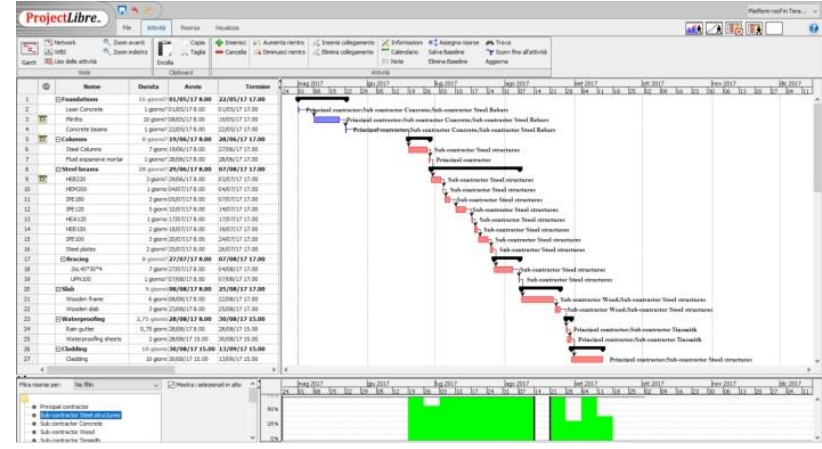

Figure 6. The Gantt diagram in ProjectLibre

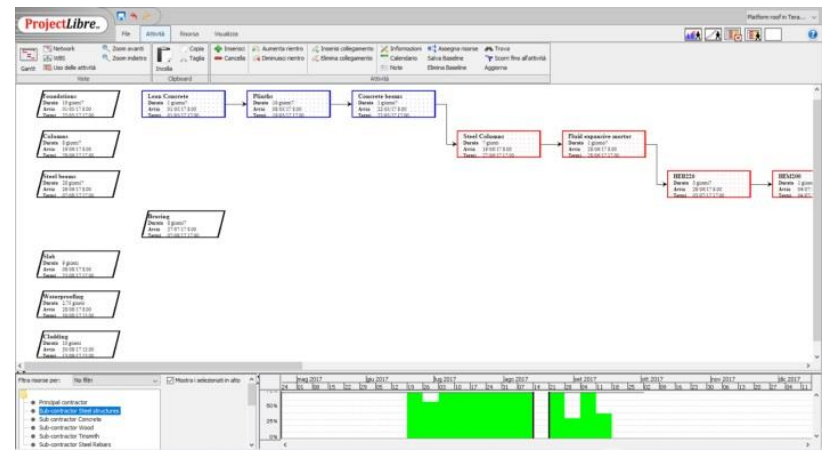

Figure 7. The Pert diagram in ProjectLibre

profiles to $2 \mathrm{~d}$ elements processed in Freecad (sketches, wires, lines or polylines) or to all the elements of each layer imported by dwg or dxf, with the return of objects structures, the same valid for the BIM model. Therefore the first step consisted in the drawing of a dxf wireframe with a CAD 2d, where central lines of the beams have been shown and divided into layers according to the types of profiles; later the model was realised through Dodo, selecting layers and assigning to each of them a specific profile. This operating mode has proved to be really fast, remedying the slow and boring design of multiple beams (Figg. 3-5). The model was improved in the Dodo workbench with appropriate macro that permitted to extend and to connect the objects created and it was completed in the BIM module to insert foundations, connections between the parts and the wooden covering panels, as well as the assignment of the materials to each single component and the BIM components. The material insertion phase revealed a bug in the program that crashed. In order to overcome this problem, the processed file was opened with version 0.16 through which it was possible to easily introduce all the information sheets related to the used materials; materials were finally assigned to BIM elements and this operation was also possible with versions 0.17 and 0.18 .

Once the model was completed, the 4D simulation started. Freecad does not have a specific area dedicated to the management of construction time phases, but in 2016 the user community developed a specific workbench, called Planner, ("Macro for BIM simulation of work - Page 3 - FreeCAD Forum," n.d.) through which it is possible to connect a Gantt chart, drawn with the Open Source software ProjectLibre, to different components of the BIM model (Tsvetkov and Petrova, 2013). In this case, Freecad works as post-processing of the data developed in ProjectLibre. The workflow is simple and it can be summarized in the following steps: in ProjectLibre a Gantt and Pert diagrams are drawn on the basis of construction phases evaluated with the CPM criterion (Critical path method) (Figg. $6,7)$; the building resources are defined and they are assigned to

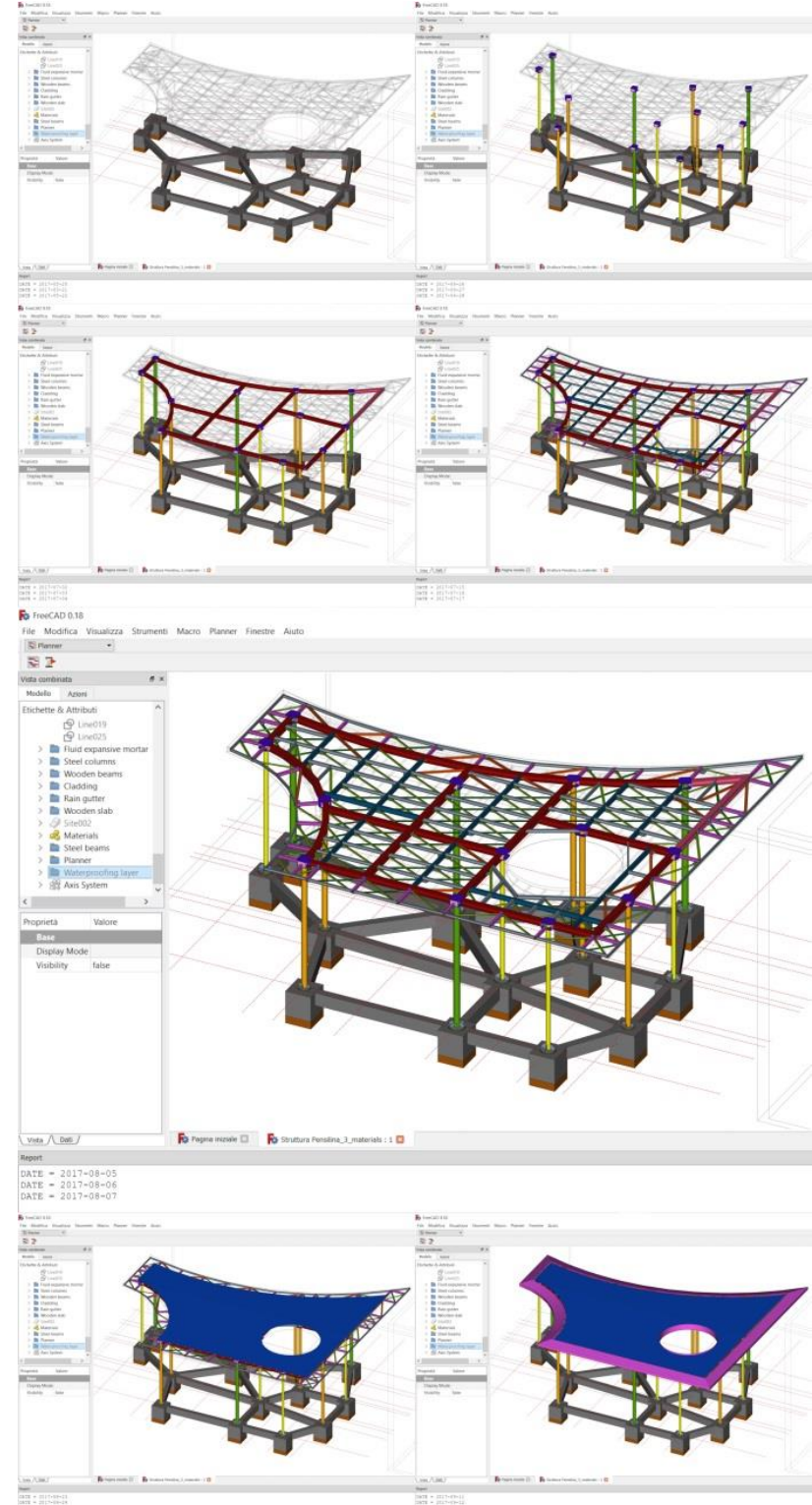

Figure 8. Building phases in Freecad according to the Gantt Diagram exported from ProjectLibre

phases; an xml file is exported from ProjectLibre and imported in Freecad within the Planner workbench; the import process includes the Freecad model with appropriate labels, named as the ProjectLibre phases; the corresponding label is assigned to each component in the properties panel; the visualisation of the 4D simulation can start. The simulation carried out through Planner has revealed another small inconvenience; indeed despite the workbench was installable and appeared in the version 0.18 , the loading of the xml couldn't be completed, so the labels couldn't be assigned to components. Also in this case the version 0.16 was used, furthermore the test was also carried out with version 0.17 which proved to be efficient. In all likelihood, the failure is due to the updating of the Python and Qt libraries. In any case, once the labels are assigned, the simulation can also be performed with the version 0.18 .

\subsection{The 4D BIM in Sketchup and Tekla Structures}

The modelling in Sketchup was carried out through a free extension, Building Structures Tool that allows a workflow similar to Dodo in Freecad. The 4D simulation was carried out 


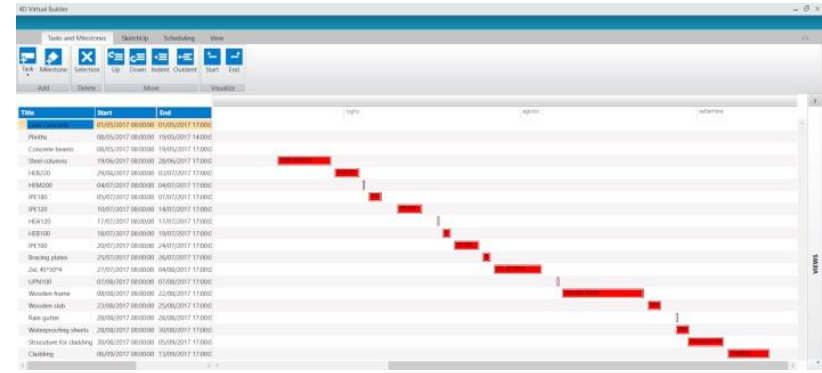

Figure 9. The Gantt chart in Sketchup via 4D Virtual Builder

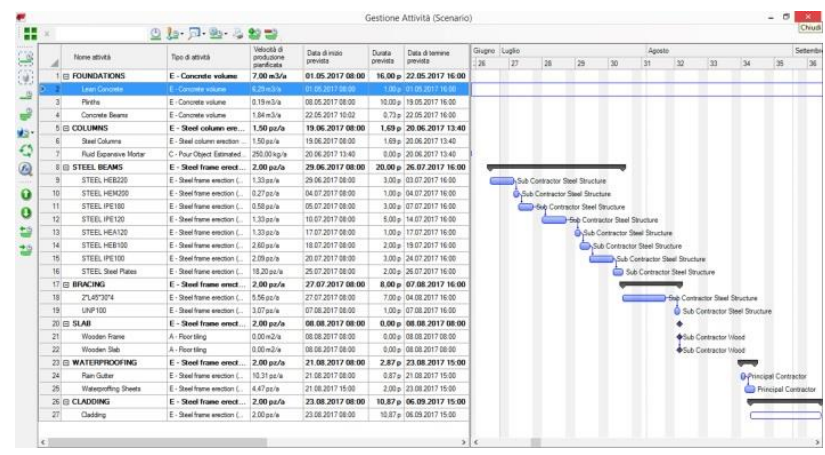

Figure 10. The Gantt chart in Tekla Structures

instead with the extension 4D Virtual Builder in trial version. The choice of this plugin was suggested by the desire to test an internal functionality of the software, without resorting to the use of external software, such as Synchro. Through 4D Virtual Builder it is possible to define phases in a Gantt chart (Fig. 9) and later to assign them to each elements of the model. The extension permits also to load the phases from xml files processed by other software such as MS Project or Asta Power Project and, unlike what happens in Freecad, allows to optimally control the visualization modalities of the construction progress related to the elements assigned to each phase, and to export the same phases in video format or in sequences of images (Fig. 10). However, it does not have a resources management module or tools that are useful to review the construction site schedule, in the case of unexpected events that may produce delays. These lacks are partially solved in Tekla Structures, that dedicates to the 4D control a specific area

of the software called "manage" in which it is possible to find all the tools connected with the construction time schedule.

The arrangement of the 4D workflow needs the division of the model components in different phases that correspond to the major parts of the construction sequences; this action may appear as a traditional layer organisation, but it allows to organise the building sequence also by other criteria like structural qualities or production and building costs, remembering that in 2019 the software is provided of a specific extension called "Design-to-cost" that is useful to make predictive analysis about the financial commitment of a building. The phases assignment directly leads to list the singular construction activities in a specific panel that is able to control several aspects of the time schedule and that could be implemented with many information concerning players and features of the building procedure.

Once created the activities list, it is possible to export it in different sort of charts (Fig. 11), but above all, to visualize the construction sequence in a timeline of hours or days, that show the consecutive steps of the construction (Fig. 12), that could be

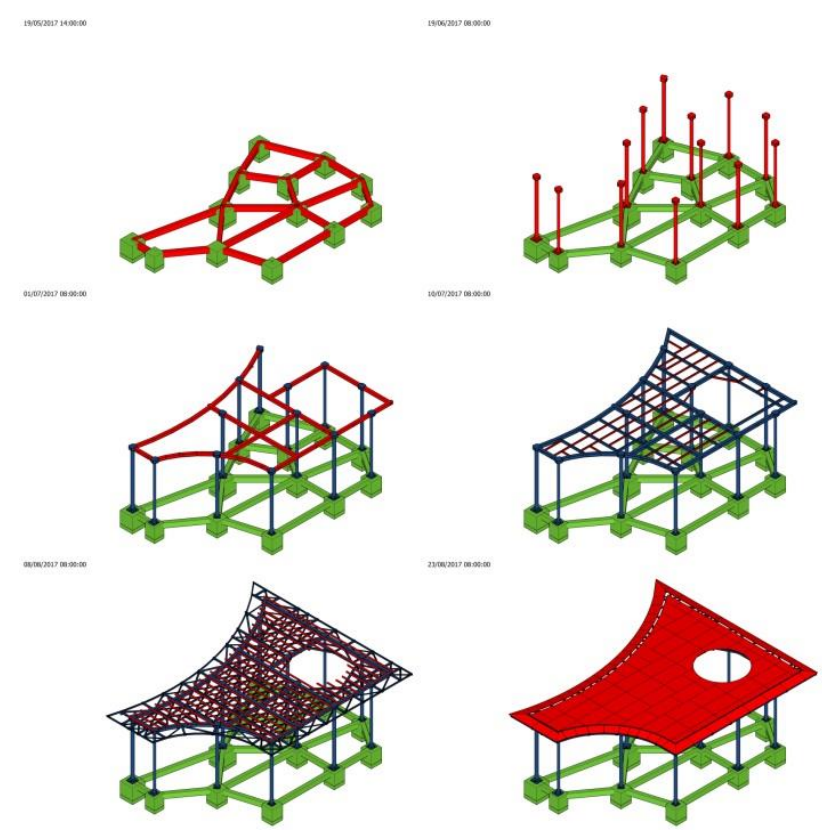

Figure 11. Building phases in Sketchup

easily converted in an animation with the Sketchup importation, with the possibility to automatically produce reports and to check the safety oriented construction process planning (Sulanviki et al., 2010).

\section{CONCLUSION}

The results of the comparison between Freecad and the other commercial software has revealed some strengths of the Open Source platforms and some critical aspects. About problems, it is clear that in Freecad pictures referring to the progress of the work aren't so attractive and well-defined in a communicative way, as allowed by Sketchup and neither the management of all the building processes, with the automatic development of the phases according to the yields related to the resources assigned to certain processes as in the case of Tekla.

However, it must be recognized that although it cannot rely on automated processes, alternative operating practices can be used in Freecad that can overcome these problems and that already make the software efficient also for a professional use.

In any case, in order to facilitate the visualization of the construction site phases, it is possible to copy the Planner group generated by the loading of the Project Libre xml file several times, and to assign them some of the phases, so as to simplify the display of singular parts, waiting for a desired improvement and adaptation of the version 0.18 and Planner. Furthermore the proposed model consisted of short beams and a large number of components, which did not ease visual operations, so the difficulty in visualization could be much less relevant in other larger models.

About the automatic management of the time of the phases, the following operating mode is proposed: it is possible to export information sheets related to the quantities from Freecad; to connect the exported file in csv to ProjectLibre; within it time of the phases is determined according to the quantity of elements and the yield of resource production (example: in the case of quantities of $200 \mathrm{mc}$ of RC and a resources efficiency of $25 \mathrm{mc} /$ day, the phase lasts 8 day) The potential of ProjectLibre is only partially exploited by Planner, because the software allows a project management that appears really advanced, even if it is not supported by the captivating graphics of similar 
commercial software. A possible development to improve the interaction between Freecad and ProjectLibre could also concern the management of the costs related to phases and resources defined in ProjectLibre, as well as the revision of the project phases in relation to delays and unforeseen events, that appears very advanced in ProjectLibre thanks to the easy management of the baselines.
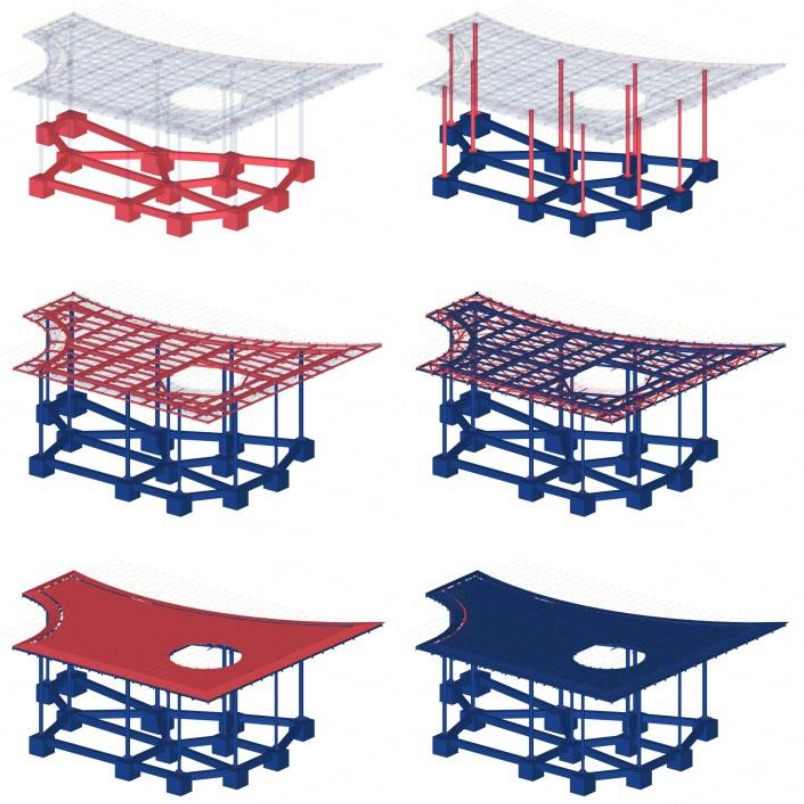

Figure 12. Building phases in Tekla Structures

\section{REFERENCES}

B-processor download | SourceForge.net (WWW Document)., n.d. URL https://sourceforge.net/projects/bprocessor/ (24 October 2019).

BIM Workbench - FreeCAD Documentation (WWW Document)., n.d. URL https://www.freecadweb.org/wiki/BIM_Workbench (25 October 2019).

Boton, C., Kubicki, S., Halin, G., 2015. 4D/BIM simulation for pre-construction and construction scheduling. Multiple levels of development within a single case study. In: Proceedings of the Creative Construction Conference 2015, Kraków, Poland, 2124 June 2015, pp. 500-505.

Dalheimer, M.K., 2002. Programming with Qt: Writing Portable GUI applications on Unix and Win32. O'Reilly Media.

DeLanda M. 2001. Open-Source: A Movement in Search of a Philosophy. https://www.cddc.vt.edu/host/delanda/pages/ opensource.htm (25 October 2019).

Di Bona, C. \& Ockman, S. 2008. Open Sources. Voices from the Open Source Revolution. Sebastopol CA: O'Reilly Media.

Eco, U. 1980. Il nome della rosa. Milano: Collana Letteraria, Bompiani.
Falck, B., Falck, D., Collette, B., 2012. Freecad (How-To)., Informatica (E-libro). Packt Pub.

Floridi, L. 1995. Internet: which future for organized knowledge, Frankestein or Pygmalion?. International Journal of Human-Computer Studies 43: 261-274.

Free Software Foundation 2018. Front Page - Free Software Foundation — working together for free software (online). https://www.fsf.org/ (10 October 2019).

Frigeri, A. Speranza, G. 2011. "Eppur si muove", Software Libero e Ricerca Riproducibile. Studi Umbri 3(1): 1-8.

Gehry, Dassault and IBM Too - Day (WWW Document)., n.d. URL

https://web.archive.org/web/20051201074232/http://www. caddigest.com/subjects/aec/select/103103_day_gehry.htm October 2019).

Graham, P. 2004. Great Hackers (online). http://www.paulgraham.com/gh.html (Accessed 09 November 2018).

Guévremont, M. and Hammad, A., 2018. Multi-LOD 4D Simulation in Phased Rehabilitation Projects. In: Proceedings of the 17th International Conference on Computing in Civil and Building Engineering (ICCCBE), Tampere, Finland, pp. 724731.

Himanen, P. 2001. The hacker ethic and the spirit of the information age. New York: Random House Trade Paperbacks. Kelty C.M. 2008. Two Bits. Durham NC: Duke University Press.

Horstmann, C.S., 2013. Python for Everyone, Wiley High School Edition. Wiley.

History - FreeCAD Documentation (WWW Document)., n.d. URL https://www.freecadweb.org/wiki/History (18 October 2019).

Koo, B. and Fischer, M., 2000. Feasibility study of 4D CAD in commercial construction. Journal of Construction Engineering and Management, 126(4), pp. 251-260.

IfcOpenShell, n.d. URL http://ifcopenshell.org/ (25 October 2019).

Jupp, J., 2017. 4D BIM for Environmental Planning and Management. Procedia Engineering, 180(1), pp. 190-201. https://doi.org/10.1016/j.proeng.2017.04.178

Levy, S. 1984. Hackers: Heroes of the Computer Revolution. New York: Anchor Press/Doubleday.

Logothetis, S., Karachaliou, E., Stylianidis, E., 2017a. From Oss cad to bim for cultural heritage digital representation. Int. Arch. Photogramm. Remote Sens. Spat. Inf. Sci. - ISPRS Arch. 42, 439-445. https://doi.org/10.5194/isprs-archives-XLII-2W3-439-2017

Logothetis, S., Valari, E., Karachaliou, E., Stylianidis, E., 2017b. Spatial dmbs architecture for a free and open source bim. Int. Arch. Photogramm. Remote Sens. Spat. Inf. Sci. - 
ISPRS Arch. 42, 467-473. https://doi.org/10.5194/isprsarchives-XLII-2-W5-467-2017

Logothetis, S., Karachaliou, E., Valari, E., Stylianidis, E., 2018. Open source cloud-based technologies for BIM. Int. Arch. Photogramm. Remote Sens. Spat. Inf. Sci. - ISPRS Arch. 42, 607-614. https://doi.org/10.5194/isprs-archives-XLII-2-6072018

Macro for BIM simulation of work - Page 3 - FreeCAD Forum (WWW Document)., n.d. URL https://forum.freecadweb.org/ viewtopic.php? $\mathrm{f}=22 \& \mathrm{t}=18612 \& \mathrm{sid}=744 \mathrm{ccae} 11951 \mathrm{~d} 13035 \mathrm{a} 47 \mathrm{a}$ c

93f85aca0\&start=20 (07 October 2019).

Markoff J. 2005. What the Dormouse Said. London: Penguin Books Ltd.

McKinney, K., Kim, J., Martin, F., Howard, C., 1996. Interactive 4D-CAD. Computing in Civil Engineering, 7(3), pp. 383-389.

Neahd, A.K., Niyaz, A.S., Syed, M.H.M., Syed, N.U., Yhsanullah, K., Comparison and analysis of a building with 4D modelling. Journal of Mechanical and Civil Engineering, 14(2), pp. 84-94.

OPEN CASCADE (WWW Document), n.d. URL https://www.opencascade.com/ (25 October 2019).

Open Source Initiative 2008. History of the OSI (online). https://opensource.org/history (06 November 2018).

Popper, K. 1974. The Open Society and its enemies. The high tide of prophecy: Hegel, Marx and the Aftermath. London: George Routledge \& Sons, ltd.

Raymond E.S. 1998. Goodbye, 'free software'; hello, 'open source' (online). http://www.catb.org/ esr/open-source.html (08 November 2018)

Raymond E.S. 1999. The Cathedral and the Bazaar. Sebastopol CA: O'Reilly Media.

Raymond E.S. et al. 2003. The Jargon File 4.4 .7 (online). http://catb.org/jargon/html/ (10 November 2018).

Releases · FreeCAD/FreeCAD - GitHub (WWW Document)., n.d. URL https://github.com/FreeCAD/FreeCAD/releases (25 October 2019).

Sampaio, A.Z., 2017. 4D/BIM linked to VR technology, In: Proceedings of the AMC Virtual Reality International Conference, Laval, France, March 2017, pp. 1-4. http://dx.doi.org/10.1145/3110292.3110298

Srdić, A. and Šelih, J., 2015. Delays in construction projects: causes and mitigation. Organization, technology and management in construction - an international journal, 7(3), pp. 1383-1389.

Stallman, R.M. 2018. GNU Emacs - GNU Project (online). Retrieved from: https://www.gnu.org/software/emacs/ (11 November 2018).
Stallman, R.M. 2018. Linux and the GNU System (online). https://www.gnu.org/gnu/linux-and-gnu.en.html (08 Nov 2018).

Stallman, R.M. 2018. The GNU Project (online). https://www.gnu.org/gnu/thegnuproject.en.html (Accessed 12 November 2018).

Stallman, R.M., Lessing, L. \& Gay, J. 2002. Free Software, Free Society: Selected Essays of Richard M. Stallman. Boston MA: GNU Press.

Stallman, R.M., Lessing, L. \& Gay, J. 2002. Free Software, Free Society: Selected Essays of Richard M. Stallman. Boston MA: GNU Press.

Sulankivi, K., Kähkönen, K., Mäkelä, T. and Kiviniemi, M., 2010. 4D-BIM for Construction Safety Planning. CIB 2010 World Congress proceedings. Barrett, P., Amaratunga, D., Haigh, R., Keraminiyage, K. \& Pathirage, C. (Eds.). CIB. http://www.cib2010.org/post/files/papers/1167.pdf.

Tsvetkov, K.S., Petrova, M.M., 2013. Is there any truth in "ProjectLibre the open source replacement of microsoft project"? Comput. Model. New Technol.

Wayner, P. 2000. Free for all: How Linux and the Free Software Movement Undercut the High-Tech Giants. New York: Harper Collins.

Webb, R.M., Haupt, T.C., 2005. The potential of 4D CAD as a tool for Construction Management, In: $4 D C A D$ and Visualization in Construction: Developments and Applications, A.A. Balkema Publishers, Lisse, Vol.1, pp. 227-243.

xBIM Toolkit (WWW Document), n.d. URL https://docs.xbim.net/ (20 October 2019). 